\title{
Aproximación multidimensional al régimen de responsabilidad internacional y al principio de no intervención. El problema hermenéutico
}

Fecha de recepción: 12 de diciembre de 2018

Fecha de aprobación: 2 de agosto de 2019

Doi: https://doi.org/10.12804/revistas.urosario.edu.co/acdi/a.7492

\section{Andrés Téllez Núñez*}

Resumen: en el contexto de la relación entre los Draft Articles on Responsibility of States for International Wrongful Acts (DAR) y los criterios de la denominada responsibility to protect (R2P), este artículo de investigación describe el problema hermenéutico de la dificultad de determinar el significado no solo de esos textos, sino también de las conductas de los Estados. Para solucionar dicho problema hermenéutico, el artículo utiliza un método multidimensional que evidencia la tensión aparente entre el principio de no intervención y los elementos de la responsabilidad internacional, y recurre a herramientas de la ley y la economía (law and economics), algunos elementos de intersección entre la teoría del derecho internacional público y las relaciones internacionales y otros de la

* Abogado y magíster en filosofía, Pontificia Universidad Javeriana (Bogotá); LL.M., Universidad de Georgetown; traductor e intérprete oficial licenciado por la República de Colombia; profesor de Derecho Internacional, Facultad de Ciencias Jurídicas, Pontificia Universidad Javeriana, Bogotá, Colombia. Miembro del Grupo de Investigación en Derecho Económico, Facultad de Ciencias Jurídicas, Pontificia Universidad Javeriana. Correo electrónico: aatellez@javeriana.edu.co. ORCID: orcid.org/0000-0002-6775-4101

Para citar este artículo: Téllez Nuñez, A., "Aproximación multidimensional al régimen de responsabilidad internacional y al principio de no intervención. El problema hermenéutico". Anuario Colombiano de Derecho Internacional (ACDI) 13, 2020, 79-104. https://doi.org/10.12804/revistas.urosario.edu.co/acdi/a.7492 
psicología del poder. El artículo propone como hipótesis de trabajo que la adscripción de significado, que el autor denomina filling, obedecerá a dinámicas políticas, y concluye afirmando la coincidencia entre el mundo del derecho y el mundo de la política.

Palabras clave: no intervención, R2P, responsabilidad internacional, ONU, hermenéutica, dignidad humana.

Multidimensional Approach to International Responsibility and the Principle of Non-Intervention. The Hermeneutical Problem

Abstract: In the context of the relationship between the Draft Articles on Responsibility of States for International Wrongful Acts (DAR) and the criteria of responsibility to protect (R2P), this article describes the hermeneutical problem entailed by the difficulty of determining the meaning not only of those texts but also of the behaviors of the states. In order to solve such an hermeneutical problem, this article tackles the problem by using a multidimensional approach that evidences the apparent tension between the principle of non-intervention and the elements of international responsibility and that covers law and economics, some factors of intersection between public international law and international relations and other factors of psychology of power. This article puts forth as a working hypothesis that the adscription of meaning, the author calls filling, responds to political dynamics, and concludes that there is a coincidence between law and politics.

Keywords: Non-intervention, R2P, international responsibility, UN, hermeneutics, human dignity.

Aproximação multidimensional ao regime de responsabilidade internacional e ao princípio de não intervenção.

O problema hermenêutico

Resumo: no contexto da relação entre os Draft Articles on Responsibility of States for International Wrongful Acts (DAR) e os critérios da denominada responsibility to protect $(\mathrm{R} 2 \mathrm{P})$, este artigo de pesquisa descreve um problema 
hermenêutico que consiste na dificuldade de determinar o significado não só destes textos, mas também das condutas dos Estados. Para solucionar dito problema hermenêutico, o artigo utiliza um método multidimensional que evidência a tensão aparente entre o princípio de não intervenção e os elementos da responsabilidade internacional, e que recorre a ferramentas de law and economics, alguns elementos de interseção entre a teoria do direito internacional público e as relações internacionais e outros de psicologia do poder. O artigo propõe como hipótese de trabalho que a filiação de significado, que o autor denomina filling, obedecerá a dinâmicas políticas, e conclui afirmando a coincidência entre o mundo do direito e o mundo da política.

Palavras-chave: não intervenção, R2P, Responsabilidade internacional, ONU, Hermenêutica, Dignidade humana.

\section{Introducción}

En el contexto del derecho internacional público, la apreciación del tiempo, por parte de los seres humanos, tiende a ser engañosa. Lo que para una persona es un periodo largo que puede vivirse como una eternidad — por ejemplo, treinta años—, en el contexto de la creación y aplicación de normas jurídicas internacionales es un lapso común. El ejemplo más evidente que puede probar esta afirmación es el proceso que supone la entrada en vigor de un tratado internacional. No son pocos los casos en que median décadas entre el momento en que se inician las negociaciones y en el que un instrumento internacional empieza a surtir efectos para los Estados negociadores y contratantes.

Esta reflexión inicial sobre la apreciación y vivencia del tiempo en el contexto del derecho internacional público permite ambientar dos asuntos. El primero consiste en examinar la contradicción aparente que pareciera darse entre el principio de no intervención ${ }^{1}$ y la responsabili-

1 Para efectos de este artículo se utilizará la descripción del principio de no intervención contenida en la Resolución 2625 de la XXV Asamblea General de la Organización de Naciones Unidas que dice así: "ningún Estado o grupo de Estados tiene derecho a intervenir directa o indirectamente, y sea cual fuere el motivo, en los asuntos internos o externos de cualquier otro. Por tanto, no solamente la intervención armada, sino también cualesquiera otras formas de injerencia o de amenaza atentatoria de la personalidad del 
$\mathrm{dad}^{2}$ internacional de los Estados, a la luz de la relación entre los Draft Articles on Responsibility of States for International Wrongful Acts (DAR) ${ }^{3}$ y los criterios de la responsibility to protect $(\mathrm{R} 2 \mathrm{P}),{ }^{4}$ confeccionados hace décadas, pero no por ello vetustos. El segundo asunto consiste en abordar una dificultad hermenéutica relacionada con saber cómo determinar los significados de las conductas de los Estados y sus agentes.

Con este artículo de investigación se pretende discutir sobre las denominadas intervenciones humanitarias, no a la luz de lo que se conoce como una aproximación clásica o tradicional, sino más bien a través de una postura multidimensional que exponga las características de la R2P en tanto y en cuanto estén relacionadas con los DAR, con un ingrediente adicional que concretaría el aporte al estado de la cuestión: especificar y procurar resolver los problemas hermenéuticos que se derivan de contraponer las nociones de intervención humanitaria, responsabilidad internacional y R2P por medio de una mirada multidimensional que abarque el derecho económico, la política internacional y la psicología social.

En ese sentido y para materializar el nuevo aporte al estado de la cuestión por vía hermenéutica, este artículo propone la siguiente hipótesis de trabajo: a pesar de los desarrollos dentro de la Comisión de Derecho Internacional (CDI) y de los esfuerzos de los tratadistas por especificar, por

Estado, o de los elementos políticos, económicos y culturales que lo constituyen, son violaciones del derecho internacional". Organización de Naciones Unidas, Resolución 2625 de 1970, http://www.un-documents.net/a25r2625.htm

2 El término responsabilidad tiene dos sentidos: uno a la luz de los DAR y otro a la luz de la R2P. La aclaración sobre el alcance de esa palabra hace parte del objeto de esta investigación.

3 Estos artículos son el resultado de un estudio minucioso sobre la responsabilidad internacional de los Estados llevado a cabo por la Comisión de Derecho Internacional. Aun cuando no tienen la forma de tratado, ya han sido tenidos en cuenta en ciertas piezas jurisprudenciales como Bosnia-Herzegovina v. Serbia y Montenegro. Corte Internacional de Justicia, Case Concerning Application of the Convention on the prevention and punishment of the crime of genocide (Bosnia And Herzegovina V. Serbia And Montenegro), http://www.icj-cij.org/ files/case-related/91/091-20070226-JUD-01-00-EN.pdf

4 En este artículo, se tendrán en cuenta únicamente los párrafos 138 y 139 de la Resolución de la Asamblea General de las Naciones Unidas 60/1 del 16 de septiembre de 2005 que de acuerdo con el Documento de Naciones Unidas A/63/677 del 12 de enero de 2009 descansa sobre tres pilares fundamentales: (i) las responsabilidades de protección del Estado; (ii) la asistencia internacional y el empoderamiento, y (iii) la respuesta oportuna y decisiva. Organización de Naciones Unidas, A 63/677 del 12 de enero de 2009, https:// undocs.org/A/63/677 
ejemplo, el alcance y la definición de unos términos en materia tanto del principio de no intervención, las intervenciones humanitarias, la R2P y la responsabilidad internacional de los Estados, solo las dinámicas políticas de cada Estado y, en general, de la comunidad de Estados, lograrán llenar (fill) de significado concreto y eficaz cada uno de esos términos. Esto habrá de implicar que los intérpretes no solo del derecho y la ley internacionales, sino también de las conductas - los hermeneutas - habrán de tener en cuenta siempre tanto el ejercicio del poder, como sus motivaciones últimas, reales o aparentes. Se concluirá que tanto los actores como aquellos que quieren develar qué hay detrás de las acciones y los discursos de aquellos vierten una serie de elementos propios de sus contextos y vivencias - en sentido amplio, significado- dentro del ámbito de las normas en virtud de la interacción y relación estrecha entre un deber ser convencional y el ejercicio cotidiano de los poderes político, militar y económico.

A las circunstancias de que (i) los DAR no son un tratado y (ii) los principios de la $\mathrm{R}_{2} \mathrm{P}^{5}$ no han sido recibidos con unanimidad por la comunidad internacional, ${ }^{6}$ en cierta medida, se une la dificultad por las enormes asimetrías militares, políticas y económicas entre Estados en el siglo XXI y que para cualquier estudioso de derecho internacional y de las relaciones internacionales resultan ser ya lugar común.

Para demostrar la hipótesis de trabajo, este artículo se divide en dos partes. En la primera, se presentan algunas aristas de derecho económico (law and economics) y los elementos políticos y psicológicos del problema hermenéutico de la no intervención, la intervención humanitaria bajo una nueva óptica y la responsabilidad internacional de los Estados, junto con referencias a los trabajos recientes de la Organización de Naciones Unidas (ONU) y de la CDI sobre este aspecto.

En la segunda parte, se expondrá el problema hermenéutico en relación con la responsabilidad de protección, particularmente la R2P, y se describirán las aristas asociadas con una lectura político-económica de la realidad jurídica, para afirmar que el filling mencionado antes siempre tendrá un contenido meramente político y que, en aras de no descuidar nunca un sano realismo que debe ser carácter notable del derecho internacional público, más que evitarse la infracción del ordenamiento

\footnotetext{
5 Ver nota 4.

6 Más adelante, se discutirán las referencias particulares al caso de algunos Estados en América Latina.
} 
internacional, lo que deberá propugnarse, en adelante, es (i) reducir el número y frecuencia de esos eventos de infracción, que no su eliminación total, lo cual parece un imposible, y (ii) delinear un conjunto de castigos y sanciones más eficiente, eficaz y efectivo.

El lector notará concomitantemente que las mismas expresiones intervención humanitaria, responsabilidad internacional y R2P en general, plantean per se problemas hermenéuticos, o sea de interpretación, significado, significado de la interpretación e interpretación del significado.?

El método escogido para adelantar la investigación supone dos cosas: por un lado, observación de la realidad y, por otro, interpretación de textos y conductas, es decir, un ejercicio hermenéutico.

\section{Intervención y responsabilidad internacional. Aproximaciones multidimensionales}

En este primer aparte se quiere presentar al lector los factores que hacen que la relación entre los DAR y los principios de la R2P sea sumamente compleja, particularmente dadas las dificultades inherentes a su interpretación y aplicación, y el actuar de los Estados en el siglo Xxi. En ese sentido, ciertas aproximaciones económicas, políticas y psicológicas pueden dar luces y guiar sobre cómo abordar esas complicaciones, siempre en el marco de un esfuerzo de comparación entre el mundo del ser (being — realidad) y el mundo del deber ser (ought — derecho).

En forma independiente del contenido doctrinal sobre intervenciones humanitarias o legítimas a la luz de una postura que se ha denominado clásica y que ambientó la confección de los DAR, ${ }^{8}$ sobre lo cual no se harán mayores disquisiciones y que McCormick liga directamente con la noción de soberanía, se quiere averiguar si la comunidad de Estados ha incurrido o no en un evento de responsabilidad internacional a la luz de los DAR, de los criterios de la R2P y, en general, del ordenamiento internacional

Ver nota 2.

8 Al utilizar la expresión clásica, se quiere significar la postura, por ejemplo, de Oscar Schachter en 1991 que antecedió los esfuerzos que se condensaron en la World Summit Outcome de 2005. Organización de Naciones Unidas, 2005 World Summit Outcome, http://www.un.org/en/development/desa/population/migration/generalassembly/ docs/globalcompact/A_RES_60_1.pdf 
vigente al dejar que un Estado no sea asistido eficaz y eficientemente por la comunidad internacional. ${ }^{9}$

\subsection{Perspectivas del derecho económico (law and economics)}

Las aproximaciones recientes consistentes en rational choice —asunción según la cual el individuo al tomar una decisión siempre buscará maximizar los (sus) beneficios - y más recientemente aquellas basadas en behavioral economics - el papel de las emociones y lo conductual en las decisiones de los individuos - y otras han venido siendo usadas con mayor frecuencia para explicar las dificultades que llevan a la creación e interpretación de normas jurídicas de derecho internacional público.

Gassama cree que simplemente no comprometerse o asumir una posición respecto de lo que está ocurriendo fuera de las fronteras de Estados Unidos (EE. UU.), por ejemplo, no es una opción, sino que debe darse. Él cree que dado el inmenso poder militar de ese país, su involucramiento con la comunidad internacional debe significar el poder hacer más bien que mal ${ }^{10} \mathrm{y}$, por supuesto, ha de considerarse si el Estado que será objeto de intervención ha prestado su consentimiento o no para ello.

En la base del estudio de Gassama se encuentra lo que Habermas tiene como un valor que es la dignidad humana y la reducción de las desigualdades e inequidades presentes en la comunidad internacional. Al momento del estudio de Gassama, el 40\% de toda la humanidad podía considerarse técnicamente pobre.

Un estudioso del derecho internacional público, particularmente en los campos de las sanciones económicas y de la responsabilidad internacional, no puede perder de vista que en el fondo de cualquier conflicto o situación, tildada de antijurídica, lo que existe es un desequilibrio (macro) económico o un atentado contra lo que generalmente pudiera denominarse derecho económico o asignación justa de los recursos escasos.

\footnotetext{
9 Un ejemplo didáctico puede ser la República Bolivariana de Venezuela. Con respecto a ese Estado, se utilizaron como herramienta de trabajo los índices publicados por Freedom House. Freedom House, Freedom in the World 2018. Venezuela, https://freedomhouse.org/ report/freedom-world/2018/venezuela

10 Bien y mal son nociones o conceptos que, por ahora y para efectos de este manuscrito, se entenderán en su sentido filosófico-axiológico, es decir, aquello que es estimable y no reprobable y aquello que no es lícito u honesto respectivamente.
} 
A eso se le unen dos cosas: primero, en un análisis costo-beneficio, ¿qué resulta más apropiado? ¿Intervenir o no intervenir? Y esto aun cuando en ocasiones la no intervención pueda resultar siendo una verdadera intervención. ${ }^{11}$ Segundo, ¿qué prima más? ¿Los intereses nacionales y los cálculos políticos internos o la realización de la dignidad humana fuera de las fronteras? ¿Qué atención le están prestando los medios de comunicación masiva a una situación de crisis humanitaria en un Estado determinado y, por consiguiente, qué beneficios obtiene la comunidad internacional, en últimas, si le presta atención a lo que sucede allí e interviene?

Gassama ya había considerado aproximaciones al respecto que coinciden con algunas preguntas que ciertos tratadistas de derecho internacional latinoamericanos ya han formulado en ocasiones previas. En torno a los seis criterios de la R2P: (i) autoridad apropiada, (ii) justa causa, (iii) intención correcta o apropiada, (iv) último recurso, (v) medios proporcionales y (vi) resultados razonables, se une algo que, desde Platón, ${ }^{12}$ pero más recientemente con tratadistas estadounidenses como Henkin, se concreta en la intersección entre derecho y política.

En efecto, de acuerdo con Henkin, law is politics y como lo afirma Gassama, los fenómenos de indeterminación e incoherencia surgirán necesariamente en los eventos de intervención. Por incoherencia, él se refiere fundamentalmente a las dificultades inherentes a la justificación del uso de la fuerza, la medida y extensión del sufrimiento de las personas y las circunstancias de modo, tiempo y lugar. Esa incoherencia tendría que ver con concretar el concepto de intervención humanitaria en situaciones que terminan evidenciando el divorcio entre el mundo del ser (being) y el del deber ser (ought), a lo que, vía Platón y Henkin, añadiríamos el mundo del poder ser o la política (might).

Gassama observa las estadísticas en materia de pobreza (su estudio indica que entre el 40 y el $50 \%$ de la población mundial vive en estado de pobreza), desarrollo humano e inequidad o desigualdad y, a través de Thomas Pogge, recuerda que ese estado de miseria no es sino el resultado

11 Sobre responsabilidad internacional por omisión, por supuesto, debe repasarse en Corfu Channel. Corte Internacional de Justicia, Corfu Channel (United Kingdom of Great Britain and Northern Ireland v. Albania), http://www.icj-cij.org/en/case/1

12 Platón dice: "¿no hay otros Estados que llevan la injusticia hasta atreverse a atentar a la libertad de otros Estados, e incluso a subyugar y poner en esclavitud a muchos de ellos?”. Platón, República (Ciudad de México, Porrúa, 2012), p. 23. 
de las decisiones políticas y económicas de parte de los actores dominantes en la comunidad global.

Thomas Pogge, citado por Gassama, defiende una obligación cuasilegal de los países ricos en materia de asistencia que se deriva de los artículos 25 (1) y 28 de la Declaración Universal de Derechos Humanos. ¿Cuál es la situación actual de un Estado que sufre una crisis humanitaria en materia macroeconómica? ¿Qué les corresponde hacer a las naciones en general o a Estados poderosos como EE. UU. o Alemania para enfrentar fenómenos de hambre o desnutrición fuera de sus límites geográficos? La respuesta, según Pogge y Gassama, se encuentra, entre otras, en estas disposiciones que son criterio interpretativo de la Carta de la ONU.

Verdier tiene un estudio interesante sobre el dilema del prisionero $y$, en ese contexto, sobre el deber de cooperación que se deriva del régimen de responsabilidad internacional, el cual explica afirmando que un resultado óptimo solamente puede obtenerse si los Estados subordinan sus preferencias individuales con el fin de lograr algo mutuamente óptimo a lo largo de una serie de interacciones. Valiéndose de una investigación de Robert Axelrod, Verdier afirma que finalmente la estrategia de tit for tat es la que viene a configurarse cuando un Estado coopera si el otro coopera o castiga si el otro castiga.

\subsection{Perspectivas político-jurídicas}

\subsubsection{Obligaciones y responsabilidad}

Sucharitkul refiere algo de ordinaria aparición cuando se estudia el tema de responsabilidad internacional de los Estados que consiste en la relativa irrelevancia de la existencia de daño o pérdida. En ese sentido, una cosa es un ilícito o wrong y, otra, la existencia de daño o lesión; en esa medida, hay una diferencia entre ser responsable y estar obligado a pagar una indemnización. Esto lo reafirma Grant, quien utiliza como ejemplo el laudo Biwater Gauff (Tanzania) Ltd. c. Republica de Tanzania, en el cual se puso de presente que un Estado al paso que puede violar un tratado bilateral de inversión, no por hacerlo, necesariamente causa un daño o pérdida.

Cualquier estudioso de derecho civil verá esto como una anomalía en la medida en que la responsabilidad bajo ese régimen supone siempre tres elementos: (i) hecho dañoso, (ii) culpa y (iii) nexo causal entre esos dos elementos, cosa que no ocurre en el contexto del derecho internacional público. Por otro lado, será necesario determinar si la obligación primaria 
cuya violación resulta en una obligación secundaria (reparar) se debe a toda la comunidad de Estados —es decir, es una obligación erga omnes que en materia de derechos humanos supondría mantener un estándar mínimo de protección y respeto por los derechos humanos - o solamente a un Estado o grupo reducido de ellos. ${ }^{13}$

En ese sentido, Grant introduce dos distinciones dignas de resaltar. La primera tiene que ver con dos subclases de obligaciones erga omnes: (i) aquellas de los Estados hacia la comunidad internacional como un todo y (ii) aquellas que existen en torno a otro u otros Estados en materia de protección diplomática. Las primeras suponen que todos los Estados están interesados en su protección y ejecución efectivas.

La segunda distinción tiene que ver con la diferencia entre obligaciones erga omnes y normas jus cogens. Alexander Orakhelashvili, citado por Grant, lleva a este último a concluir que ambas no son sino dos caras de la misma moneda en la medida en que ambas se relacionan con todos los Estados. Al paso que las obligaciones erga omnes provienen de normas imperativas, el proceso inverso no siempre se da. A pesar de todas estas distinciones y diferencias, Sucharitkul concluye su estudio afirmando que una línea de separación completa entre responsabilidad y obligación en la realidad resulta difícil. Weiss tiene un estudio similar sobre obligaciones erga omnes y eventos de responsabilidad aun en casos en los cuales no ha habido lesión o pérdida.

Sobre esta base, la inacción, ora de la comunidad internacional, ora de un Estado en particular en relación con la situación de uno que sufra una crisis humanitaria, podría suponer un evento de responsabilidad (responsibility), pero no necesariamente de obligación de reparación (liability).

\subsubsection{La seguridad colectiva}

Boon afirma con razón lo sorprendentemente relevante que resulta ser el compendio normativo sobre responsabilidad internacional en materia de seguridad colectiva por cuatro razones principales: (i) el aparente conflicto que se daría entre acciones del Consejo de Seguridad de la ONU (CS) y las violaciones a los derechos humanos; (ii) la circunstancia que el

13 Sobre esto puede consultarse Barcelona Traction. Corte Internacional de Justicia, Barcelona Traction, Light and Power Company, Limited (Belgium v. Spain) (New Application: 1962), http://www.icj-cij.org/en/case/50 
artículo 103 de la Carta de la ONU — la cual prevalece sobre cualquier otro tratado internacional — cada vez se invoca más para excusar violaciones de derecho internacional; (iii) la obligación secundaria de reparación que se seguiría de dichas violaciones, y (iv) el papel mediador entre el derecho penal internacional y las reglas sobre seguridad colectiva en relación con el crimen de agresión.

A su vez, dentro de la misma arquitectura internacional se daría una suerte de conflicto de interpretación y aplicación por tres circunstancias que Boon llama respectivamente (i) embeddedness, es decir, la existencia de múltiples regímenes que tocan obligaciones de derechos humanos que se encuentran incrustadas allí; (ii) strategic inconsistency, es decir, aquella circunstancia en la cual los Estados acuden a diferentes regímenes para salvaguardar de manera estratégica y mejor para ellos sus intereses, y (iii) separate legal personality, es decir, atribuir responsabilidad internacional a una entidad compuesta de otras entidades y no a las entidades propiamente dichas.

Sobre esto, el autor se pregunta si en virtud de cumplir con lo estipulado en el artículo 103 de la Carta de la ONU, un Estado podría liberarse de responsabilidad internacional por precisamente haber "cumplido" con sus disposiciones; a esto responde negativamente.

Todo ello viene a precisarse en este siglo en tres elementos concretos y directamente relacionados con la responsabilidad internacional: (i) la necesidad de los Estados de introducir e implementar medidas contra el terrorismo, tal y como lo ordena, por ejemplo, la Resolución 1267 de 1999 del cs; (ii) las demandas de reparación iniciadas por individuos que implican la revisión por parte de jueces y tribunales de las resoluciones del capítulo VII de la Carta de la ONU, y (iii) la decisión sobre si ha habido o no agresión.

Grant, a la luz de su estudio sobre los Draft Articles on Responsibility of International Organizations (DARIO), cree que la práctica de la ONU en torno a la admisión de nuevos miembros ha considerado muy poco si ha habido eventos de responsabilidad internacional por parte de los Estados que buscan ser parte de esa entidad.

Por otro lado, existen los mismos elementos que se tienen en cuenta al hablarse de responsabilidad internacional de los Estados bajo los DAR, es decir, una obligación primaria, la violación de esa obligación primaria y el atribuirla a una organización internacional con lo cual se configura un evento de responsabilidad internacional, pero con una dificultad evidente: no todos los Estados que son miembros de una organización 
internacional o, incluso dos o más organizaciones internacionales, están regidos por los mismos instrumentos internacionales. Además, esto está sujeto a cambios en el tiempo en la medida en que dichos Estados y organizaciones internacionales pueden buscar la terminación de estos. Es el caso de Estados que deciden retirarse de organizaciones internacionales cuando estas parecen actuar en contravía de sus intereses.

Grant ve un problema evidente consistente en que las organizaciones internacionales no son parte de un gran número de los tratados multilaterales y ello plantea, de entrada, un problema de interpretación y aplicación de los DARIO, que únicamente puede ser solucionado, afirma Grant, mediante el recurso al derecho consuetudinario.

Cualquier estudio en materia de responsabilidad de los Estados no puede dejar de considerar, según McCormick, el procurar lograr un equilibrio entre el respeto por la soberanía de ellos y la salvaguarda y protección de los derechos humanos. En esto, necesariamente, debe considerarse el problema debatido ya en varias ocasiones que se refiere a las llamadas intervenciones humanitarias, que vienen a estar enmarcadas, según McCormick, por la Resolución 43/131 de 1988 y por la Resolución 45/100 de 1990, ambas expedidas por la Asamblea General de la ONU.

\subsubsection{Soberanía y territorio como factores determinantes en la responsabilidad de protección}

En el marco de la discusión sobre la soberanía de los Estados, y a manera de hilo conductor en relación con lo que han sido sus esfuerzos por acometer una reflexión jurídica sobre el problema de la responsabilidad, se ha concluido que ese atributo en ningún caso debe ser una "licencia para matar", en palabras de Gareth Evans citado por McCormick.

La llamada R2P, cuyos elementos se detallarán en los párrafos posteriores, fue fruto del trabajo del International Crisis Group (ICG) a principios de siglo XXI y su versión light fue adoptada en el Outcome Document de la World Summit de 2005. Ella supone que los Estados deben proteger a sus propios ciudadanos de la comisión de cuatro categorías de crímenes conjuntamente referidos como crimenes atroces. En la medida en que los Estados no cumplan con esa obligación, la comunidad internacional debe velar no solo porque ella se cumpla, sino también por sancionar y castigar a los responsables de su violación. En palabras sencillas: nunca un Estado podrá alegar su propia soberanía y con ese pretexto, violar los derechos humanos de sus nacionales y ciudadanos. 
Venezuela, a fines del siglo xx y principios del XxI, es un buen ejemplo para ilustrar cómo el discurso político se centra en la soberanía y en su respeto, pero las acciones suponen la violación de la dignidad humana de las personas, sobre todo, de aquellas que han sido identificadas como opositoras al régimen.

La conducta de los Estados, entonces, vendría a estar delimitada por cuatro principios de precaución que se podrían resumir así: (i) intención correcta (appropriate) de que el sufrimiento humano no continúe; (ii) considerar las intervenciones armadas o militares como un último recurso (last resort); (iii) que haya proporcionalidad lo cual significa que haya la mínima intervención militar necesaria (proportionality), y (iv) que haya posibilidades razonables de detener o evitar el sufrimiento humano (successful outcome).

Todos estos elementos o principios vendrían además a estar enmarcados por una justa causa y por la circunstancia de que cualquier acción que busque salvaguardar la dignidad humana, es decir, cualquier intervención que busque proteger los derechos humanos, debe provenir de la autoridad apropiada.

El lector podrá ya sospechar o adivinar que estos cuatro principios de precaución dan la posibilidad de hacer un examen hermenéuticosemántico. Este se desarrollará en el segundo apartado del manuscrito.

El Outcome Document referido ya en párrafos precedentes, es una versión light del documento del ICG y sus elementos principales se pueden resumir de la siguiente manera: (i) no hay una responsabilidad secundaria formal por parte de la comunidad internacional en torno a reaccionar a violaciones de derechos humanos que ocurran a lo largo del planeta; (ii) si el CS no la autoriza, la intervención no puede darse (al contrario de lo que proponía el documento del ICG); (iii) un Estado debe evidenciar una falla manifiesta (manifest failure) frente a la protección de sus propios ciudadanos antes de que se autorice una intervención foránea, y (iv) solo se cubren genocidio, crímenes de guerra, limpieza étnica y crímenes en contra de la humanidad.

El autor coincide con McCormick, quien luego de examinar la obra de James Pattison: Humanitarian Intervention and the Responsibility to Protect, arguye que el fenómeno de la globalización hace que todos los Estados se vean afectados por los acontecimientos internos de las vidas de los otros y que precisamente lo que ella llama Estados débiles en desarrollo, debieran impulsar la confección de un tratado multilateral, que proteja los derechos humanos, pero que impida que Estados poderosos intervengan 
en sus propios asuntos y en defensa única de sus intereses. Sin embargo, como lo verá reiterado el lector en la segunda parte del artículo, el autor considera que esa posición es utópica.

Preguntémonos si un Estado cuyo gobierno viola sistemáticamente los derechos humanos estaría dispuesto a suscribir un tratado en virtud del cual se delimiten los eventos de responsabilidad por violación de derechos humanos y se permite que otros Estados asuman la defensa de ellos o castiguen los ilícitos correspondientes o en el caso en que aceptare ser parte de un instrumento tal, si no habría maniobras interpretativas sobre qué significa el término derechos humanos o qué significa protegerlos.

Pregúntese, así mismo, si un Estado poderoso como EE. UU., estaría dispuesto a aceptar que otros se inmiscuyeran en sus asuntos internos alegando violaciones a los derechos humanos en su territorio, como las que se dan cuando muchos de sus nacionales no tienen derecho a acceder al cuidado de su salud (Obamacare) o cuando los hijos de migrantes ilegales son separados de sus padres, argumentando para ello que eso es lo que mandan y prescriben las leyes federales estadounidenses.

Quizás una forma menos ineficiente sería adecuar los instrumentos actualmente existentes, como la Carta de la Organización de Estados Americanos (Carta de la OEA) a los principios de precaución, pero ahí nos encontramos nuevamente con la confluencia de voluntades políticas diferentes y con el problema hermenéutico que constituye el quid de esta investigación.

De pronto, un profesor de derecho internacional podrá compartir la experiencia en el aula de clase cuando a los alumnos se les dice que la idea subyacente y clave de todo el derecho internacional moderno se materializaría en la noción de territorio y que todos los esfuerzos jurídicos y legales giran alrededor de ella. Szigeti coincide con el autor y denomina este fenómeno sesgo territorial. Esto podría resumirse afirmando que el derecho internacional debe estar en capacidad de responder a la pregunta acerca de si la protección de los derechos humanos debe ser algo que concierna a los Estados únicamente dentro de sus fronteras o también fuera de ellas.

En su estudio del DAR, él divide la atribución de responsabilidad de los Estados a partir de cuatro principios: (i) asignación de responsabilidad por virtud de la voluntad soberana (cita para el efecto los artículos 6, 8, 10 y 11); (ii) asignación de responsabilidad según el estatus de la agencia estatal y de acuerdo a las leyes de un Estado (artículos 4 y 7); (iii) asignación de responsabilidad en virtud de una persona que lleva a cabo funciones 
públicas (artículos 5-9), y (iv) asignación por virtud del control territorial (cita todos los artículos de DAR precedentes excepto los artículos 8 y 11).

Su estudio interesa no tanto por su examen sobre la atribución de responsabilidad, sino más bien por una reflexión que es de mucha utilidad para efectos del análisis hermenéutico que aquí se presentará. Dice Szigeti que cuando un abogado busca determinar el significado de los actos de un Estado resulta difícil saber si las personas que actúan "a nombre del Estado" realmente lo hacen así.

\subsubsection{El problema de la autoridad moral}

En el marco de su estudio sobre intervenciones humanitarias, Gassama habla de una evolución que ha ido desde el derecho de intervenir hasta la responsabilidad de proteger, pero aclara que el cambio de terminología no ha supuesto, ni siquiera significado, que los más vulnerables de la población de un Estado cualquiera sean efectivamente protegidos.

Al paso que los desarrollos tecnológicos acelerados en las últimas dos décadas y el deterioro evidente del medio ambiente plantean más que problemas, que son razones para reflexionar sobre las intervenciones humanitarias desde el punto de vista filosófico-político, si se entiende bien a Gassama, lo que ocurre es que siempre habrá una crítica sobre las motivaciones de los Estados o de las organizaciones internacionales que buscan intervenir, y se resaltará o criticará, sobre todo, su autoridad moral.

Sobre esto, Gassama refiere los estudios de Kok-Chor Tan y Carla Bagnoli. De acuerdo con Carla Bagnoli, citada por Gassama, siempre que se estén violando los derechos humanos hay un deber moral de intervenir. Esto supone decidir, en la medida en que estamos al frente de un sistema axiológico, qué vale y qué no vale, qué es valioso y qué no lo es. Por otro lado, Kok-Chor Tan anota que la permisibilidad no supone la generación de una obligación, es decir, la posibilidad de intervenir no significa que haya un compromiso legal de hacerlo.

A ese que se estima como un problema filosófico-jurídico que tiene que ver con la autoridad moral de los Estados y de los dirigentes que abogan por una intervención que sea tildada de humanitaria se uniría otro más complejo, cree el autor, que tiene que ver con la lectura e interpretación de la realidad a través de un discurso y su comparación con las acciones de seres humanos de carne y hueso y lo que muestra el mundo material.

Dos ejemplos pueden ayudar a ilustrar este problema filosóficojurídico: un Estado poderoso como EE. UU. puede argumentar que intervenir 
económica y militarmente en un Estado como Venezuela es lo que correspondería, dadas, por ejemplo, las violaciones probadas de los derechos humanos - sobre esto, el lector podrá consultar los informes de la ONU de 2019 preparados con base en verificaciones in situ—o los pésimos indicadores económicos. Un enemigo de las políticas intervencionistas de EE. UU. podría argumentar que dentro de ese país también se violan los derechos humanos y que no hay autoridad moral. Así mismo, dicho enemigo puede argumentar que el discurso estadounidense es equivocado y que simplemente en Venezuela no hay violaciones de derechos humanos, la prosperidad económica es evidente, los colombianos, por ejemplo, quieren migrar hacia ese territorio y la Constitución y las leyes siempre se cumplen y se obedecen.

¿Cómo rebatir una u otra caracterización? ¿Cómo determinar la verdad de las afirmaciones de uno u otro gobernante? ¿Cómo adscribir responsabilidad internacional, por ejemplo, de EE. UU., que prefiere reunirse con Corea del Norte que intervenir incluso militarmente en Venezuela?

Bradford y Posner hablan de la moralidad política al cuestionar el actuar de EE. UU. en el concierto internacional. Esto tendrá implicaciones para el presente estudio al hablar sobre la cooperación y el deber del más fuerte de promover al débil y no de anularlo.

\subsubsection{Psicología y poder}

Nelson reconoce que el fuerte o poderoso impondrá su voluntad sobre el débil y describe el poder como la habilidad de un actor " $\mathrm{A}$ " de lograr que un actor "B" haga algo que "B" de otra forma no haría. Cita un estudio adelantado por Bertram Raven y John French que identifican cinco bases de poder social: coercitivo, de recompensa, legítimo, referente y del experto.

Aun cuando no se hará una disección minuciosa sobre los aspectos psicológicos que mueven a los Estados y a sus representantes a actuar de una u otra forma y que, por ejemplo, implican tener en cuenta no solo sesgos cognitivos, sino también disonancias $\operatorname{cognitivas}^{14}$ que se ponen

14 Se entienden como sesgos y disonancias cognitivas respectivamente una desviación de la racionalidad al momento de emitir un juicio y la inconsistencia entre pensamientos, creencias y acciones. Un ejemplo de sesgo cognitivo podría ser la adopción de una política antiinmigrantes porque aquel que la diseña fue víctima de un ataque por parte de un inmigrante; un ejemplo de disonancia cognitiva podría ser defender la prohibición de fumar porque hace daño, pero fumar todo el tiempo. 
de presente en una reunión bilateral entre jefes de Estado y se pueden inferir del lenguaje corporal o de si ellos perciben o sienten simpatía mutua, etc. - al considerar que los Estados siempre actúan a través de sus agentes-, tener en cuenta el apoyo del pueblo a un gobernante en torno a una intervención que a todas luces sea humanitaria, qué tan buenas relaciones personales hay entre los dirigentes, el miedo a una acción u omisión o al uso de la fuerza, todos esos son factores que deberán ser examinados, cada vez más, para poder discernir y adscribir significados más precisos y correctos a las acciones de los Estados y sus representantes.

\subsubsection{Desarrollos institucionales recientes}

Se quieren destacar dos desarrollos relativamente recientes: (i) el reporte del Secretario General de la ONU de 2009, citado anteriormente, que expone los tres pilares sobre los cuales descansa la R2P y que se pueden resumir de la siguiente manera: (a) la responsabilidad de un Estado de proteger a su población, sean nacionales o no, de genocidio, crímenes de guerra, limpieza étnica y crímenes contra la humanidad, y con la necesidad de diseñar estrategias apropiadas para ello; (b) el deber de cooperación referenciado a lo largo del manuscrito, y (c) la respuesta eficiente haciendo uso de las herramientas institucionales de la ONU soportado en el ejemplo de Kenia a principios de 2008.

El otro desarrollo (ii) lo constituye el reporte de la sexagésimo novena Sesión de la CDI de 2017 sobre responsabilidad internacional en materia de sucesión de Estados - First Report on Succession of States in Respect of State Responsibility - del cual solo se quieren resaltar dos elementos: (a) el reconocimiento en su parágrafo 85 del alto componente político del tema y (b) los planes para 2018, 2019 y 2020 en torno a las obligaciones de un Estado sucesor en materia de causación de obligaciones si hay disolución o unificación, los derechos de un Estado predecesor respecto de un Estado sucesor y la responsabilidad compartida, todo lo cual se expone detalladamente en su capítulo III del reporte.

Con las secciones anteriores se ha procurado ambientar las discusiones sobre intervención humanitaria a la luz de los DAR y la R2P, desde una perspectiva multidimensional que lidia con las condiciones económicas de los pueblos, el tipo de obligaciones que tienen los Estados con la comunidad internacional, sus atributos como la soberanía con el fin de argumentar a favor de una intervención o de atacarla y, por último, el papel de la psicología del poder y la influencia de los desarrollos recientes, 
particularmente de la última década, en materia de responsabilidad. En el próximo apartado se utilizarán estas herramientas para procurar solucionar lo que se ha denominado el problema hermenéutico en materia de responsabilidad internacional.

\section{E1 problema hermenéutico}

En esta segunda sección se quiere reflexionar sobre el problema ya ambientado en torno a la existencia de dos aparentes conflictos: (i) aquel entre el discurso (político) y las acciones de los Estados o de sus representantes en relación con la responsabilidad internacional con un énfasis en la conexión entre los DAR, los DARIO y la R2P que se precisa en dos artículos concretos referidos a jus cogens ${ }^{15}$ y (ii) aquel entre significantes y significados. Para resolver el problema hermenéutico, es decir, cómo adscribir justamente o, más bien, interpretar correctamente el actuar de un Estado, el lector encontrará algunos elementos de análisis para arribar a una conclusión cuyos ejes fundamentales son la dignidad humana como valor y la existencia de sufrimiento y dolor físico y psicológico como consecuencia de su violación.

\subsection{Relación entre dos tipos de responsabilidad. Discurso versus acción y acción versus poder}

Anteriormente con Szigeti se examinó tangencialmente lo que se llamó una suerte de fenomenología hermenéutica en materia de derecho internacional. ${ }^{16}$ ¿Qué es lo que la comunidad internacional está presenciando en un momento determinado? ¿Cómo extraer el significado apropiado en torno a las conductas tanto de personas de carne y hueso como de Estados? ¿Qué le corresponde hacer a un abogado internacionalista para que se realicen valores tan caros como la justicia y la dignidad humana? En síntesis: ¿cómo rebatir jurídicamente las palabras y acciones de un dictador o un demagogo?

\footnotetext{
15 Es decir, las normas imperativas de derecho internacional público.

16 En otras palabras, una aproximación filosófica que se puede importar al derecho en virtud de la cual se examinen los significados de los textos y las conductas como entidades aparte del sujeto que acomete dicho examen. Hasta qué punto esto sea posible tanto en la filosofía como en el derecho todavía queda por probarse y responderse más amplia y adecuadamente.
} 
Szigeti refiere en su estudio el estándar del país más desarrollado que en su opinión fue reafirmado por la Corte Internacional de Justicia (CIJ) en Nicaragua. ${ }^{17} \mathrm{Si}$ se entiende bien aquello que refiere Szigeti, en la evaluación hermenéutica deben atenderse circunstancias sociales, políticas y económicas de países con ciertos estándares para lograr juzgar valorativamente una conducta. Esto, según James Crawford citado por Szigeti, podría tener ciertas debilidades que podrían tildarse de antidemocráticas y resumirse de la siguiente manera: (i) las ramas ejecutivas de los Estados tienen poder casi exclusivo en materia de dirección y conducción de las relaciones internacionales; (ii) prevalencia del derecho internacional sobre la legislación más consensuada y democrática posible dentro de un Estado; (iii) facultades de la rama ejecutiva en materia de recursos y remedios; (iv) el principio de no intervención que no hace distinción alguna entre regímenes democráticos y no democráticos; (v) la posibilidad de un gobierno de vincular a un Estado internacionalmente perpetuamente, $y$ (vi) los límites a la autodeterminación que supone el uti possidetis.

En un estudio muy completo sobre la perspectiva latinoamericana, Arredondo resume las aristas no solo de la R2P, sino también de la política exterior en este subcontinente que estaría marcada por seis características: (i) la igualdad soberana de los Estados; (ii) la no intervención; (iii) la integridad territorial; (iv) la autodeterminación de los pueblos; (v) la resolución pacífica de las controversias, y (vi) el respeto por el derecho internacional.

Arredondo, no obstante, se pregunta por la aparente contradicción entre esas aristas, particularmente la no intervención y la protección de los derechos humanos y cita el artículo 3 (e) de la Carta de la OEA. Este autor utiliza para apoyar sus afirmaciones el caso de países como Venezuela, Nicaragua, Bolivia y Ecuador como ejemplos de Estados que se han opuesto a los dictámenes y principios de la R2P.

La perspectiva latinoamericana del derecho internacional resulta de mucho interés y por ello debe tenerse en cuenta el estudio de Arredondo. El actuar de EE. UU., siempre relevante en la comunidad internacional, supone, según Bradford y Posner, diferenciar entre exceptionalism y exemptionalism. Para un examen de la moralidad, esta distinción resulta útil. ${ }^{18}$

17 Corte Internacional de Justicia, Military and Paramilitary Activities in and against Nicaragua (Nicaragua v. United States of America), http://www.icj-cij.org/en/case/70/judgments

18 Si se entendió bien a Bradford y a Posner, una cosa es que haya excepciones y otra que haya exenciones. En opinión del autor, EE. UU. no solo es el ejemplo perfecto de 
¿Cómo debe proceder entonces un abogado internacionalista para argumentar respecto de un caso de intervención en un Estado en donde se violan sistemáticamente los derechos humanos?

En la obra titulada The Law of International Responsibility, editada por James Crawford et al. y examinada por Murphy, se presenta una arista sobre la cual se quiere hacer énfasis y que deriva del cumplimiento de las normas de jus cogens. Es precisamente ahí donde Jorgensen ve la íntima relación que hay entre los DAR y la R2P, particularmente, los artículos 40 de DAR y el 41 de DARIO. ${ }^{19} \mathrm{Al}$ paso que, según Jorgensen, la R2P requiere siempre una respuesta institucional de la ONU, las obligaciones de DAR y DARIO parecen tener un carácter más independiente. En opinión de Jorgensen, los regímenes de la R2P y de los DAR-DARIO se refuerzan mutuamente y el primero le da una suerte de fuerza moral al segundo. Sin embargo, en opinión del autor, apoyada por el estudio histórico de las normas jus cogens adelantado por Nieto-Navia, una lectura menos textual de todos los párrafos supondría que siempre que haya violaciones de derechos humanos, habría a su vez, violaciones de normas jus cogens por cuanto se está violando la Carta de la ONU. ¿Qué determina si hay o no intervención? Es lo que se ha procurado dilucidar, independientemente de la categorización de crímenes o ilícitos mencionados anteriormente.

En materia de ilícitos cometidos dentro de un Estado, el deber de cooperación entre Estados resulta ser una pieza del rompecabezas fundamental. De acuerdo con Verdier, el régimen de responsabilidad internacional tiene como función primaria facilitar la cooperación racional entre estos.

\subsection{Significantes y significados}

Sucharitkul distingue entre responsabilidad y obligatoriedad. A la par que la primera expresión supone determinar si hay o no un ilícito (wrong), la segunda supone la obligación de reparar y/o indemnizar (reparation).

exceptionalism en el sentido negativo del término y en el contexto del derecho internacional, sino también de búsqueda continua de exemptionalism en materia de sus obligaciones internacionales.

19 Comisión de Derecho Internacional, Draft Articles on Responsibility of States for International Wrongful Acts, http://legal.un.org/ilc/texts/instruments/english/commentaries/9_6_2001.pdf

Comisión de Derecho Internacional, Draft articles on the responsibility of international organizations, http://legal.un.org/ilc/texts/instruments/english/draft_articles/9_11_2011.pdf 
El régimen de obligatoriedad se contraería al derecho romano, particularmente concretado en la máxima sic utere tuo ut alienum non laedas, que significa usar la propiedad privada de manera que no dañe a otros. Esta distinción es apenas uno de los muchos ejemplos en los cuales el lenguaje hace difícil la interpretación de la conducta de los Estados y de los textos normativos.

Para acometer ese ejercicio, Sucharitkul presenta un contexto histórico de los esfuerzos por codificar la normatividad en materia de responsabilidad internacional que se centraban en proteger los intereses de países desarrollados sobre la explotación de los recursos naturales de países en desarrollo.

Por otro lado, Verdier refiere algo común en el contexto de las relaciones internacionales cuyo estudio, según él, viene a estar más cerca del derecho internacional; afirma que la incertidumbre se genera alrededor del significado y las consecuencias de las acciones de Estados rivales, lo cual puede resultar en lo que él llama defections (defecciones). Este, cree el autor, es el problema hermenéutico. Un par de ejemplos pueden ayudar a ilustrar esta dificultad. Ejemplo 1: el presidente de EE. UU. decide subir los aranceles del acero y con eso, a los ojos de Canadá, se afectan los intereses de este último. Ejemplo 2: el presidente de EE. UU., argumentando el cumplimiento de las leyes federales de su país, separa a padres e hijos que han entrado ilegalmente al territorio estadounidense.

Aparentemente en los dos ejemplos habría eventos de responsabilidad internacional y la comisión de ilícitos. De acuerdo con Verdier, el régimen de responsabilidad internacional lo que buscaría, entre otras cosas, sería facilitar la cooperación racional entre Estados. ¿Cómo lee el primer ministro de Canadá las acciones del presidente de EE. UU.? ¿Conducirán esas acciones a esquemas de cooperación? ¿No suele ocurrir más bien que, como afirma Nelson, el fuerte impondrá su voluntad sobre el débil?

Las dificultades propias de los DAR son examinadas por Caron, quien afirma algo que también pone de presente el problema hermenéuticointerpretativo: aplicar abstracciones académicas a situaciones concretas.

Este examen lo hace Caron en el contexto de la comparación que hace entre los DAR y lo que son propiamente tratados y la función de codificación adelantada por la CDI que parece, según él, tener mayor influencia que una convención internacional. En últimas, la entidad con mayor poder político y económico en relación con eventos de responsabilidad internacional no cumplirá con los dictados normativos o cuasinormativos, o utilizará ilícitos actuales o anunciados como una estrategia de negociación. 
Eso es lo que puede ocurrir en el caso de los dos ejemplos mencionados anteriormente. La pregunta que debe resolver el hermeneuta es la siguiente: ¿dónde queda entonces el derecho internacional?

En estos párrafos se vio la conexión entre los DAR, los DARIO y la $\mathrm{R} 2 \mathrm{P}$ concretada como lo afirma Jorgensen en los artículos 40 y 41 de los dos primeros respectivamente y se demostró que una forma jurídicamente satisfactoria de disociar el mundo del deber ser (ought) y el mundo del poder ser (might) podría resultar de la verificación de si hay o no violación de la dignidad humana, que se materializa en sufrimiento y dolor y de constatar si hay o no ayuda del más fuerte en favor del más débil, que no sea fruto de una estrategia de negociación y que, por ello, no consulte precisamente la protección de la dignidad humana como valor.

\section{Conclusiones}

Con este artículo, se han querido lograr dos cosas: (i) exponer un puente de conexión entre los DAR-DARIO y la R2P, que como se vio, se centra en el cumplimiento de normas de jus cogens, y (ii) poner de presente las dificultades hermenéuticas que se derivan de la interpretación no solo de textos, sino también de conductas de los Estados y sus agentes; dificultades que pueden resolverse recurriendo, por ejemplo, a herramientas provistas por el derecho económico (law and economics) y por la psicología del poder.

A pesar de los esfuerzos de la comunidad internacional, no hay consenso sobre todo en relación con la aplicación y exigencia de las disposiciones fundamentalmente normativas de uno y otro régimen, confirmando lo que constituye el quid de la presente investigación, que consiste en la coincidencia del reino de lo político (might) y de lo jurídico (ought). $\mathrm{El}$ autor cree que los Estados y sus agentes, máxime en torno al asunto de las intervenciones humanitarias y la adscripción de responsabilidad internacional, tenderán a llenar de un significado muy particular (filling) los términos que se usan en los instrumentos y sus propias conductas: lo que el presidente de EE. UU. llama proteger la seguridad nacional, el presidente de Venezuela lo llamará violación de los derechos bumanos; lo que el dictador norcoreano llama protección, el presidente de EE. UU. lo llamará amenaza.

El hermeneuta y, particularmente el experto en derecho internacional, no habrá de hacer demasiado caso a las palabras, sino más bien a las acciones y observar dos cosas: (i) si hay o no sufrimiento humano 
lo cual comporta dolor físico y psicológico ${ }^{20}$ como consecuencia directa de mancillar la dignidad humana y (ii) si el más poderoso en términos de recursos económicos y militares está cooperando con el más débil, para efectos de que se realice la dignidad humana y no como una estrategia racional de negociación. Si hay sufrimiento humano, es decir, entre otras cosas, hambre, muerte y destrucción, y si el más poderoso no coopera con el más débil podrá estar cierto el jurista y el hermeneuta acerca de que el derecho internacional público se está violando y, por lo menos, la sensación incómoda que ello comporta siempre probará su validez y su necesidad.

$\mathrm{El}$ autor cree que el tema de efectividad y validez del derecho internacional público deberá ser abordado en futuras investigaciones cada vez más sobre pilares proporcionados por la economía del comportamiento (behavioral economics) y, sobre todo, por la psicología y por la filosofía del lenguaje.

\section{Referencias}

Arredondo, Ricardo. "Responsibility to Protect: A Latin American Perspective." Soutbwestern Journal of International Law 20, (2014): 347-379.

Basic, Nedzad. "International Law and Security Dilemmas in Multiethnic States." Annual Survey of International \& Comparative Law 8, (2002): $1-32$.

Boon, Kristen E. "Regime Conflicts and the UN Security Council: Applying the Law of Responsibility", George Washington International Law Review 42, (2010): 787-833.

Bradford, Anu \& Posner, Eric A. "Universal Exceptionalism in International Law." Harvard International Law Journal 52, (2011): 1-54.

Brown Weiss, Edith. "Symposium - The ILC's State Responsibility Articles: Invoking State Responsibility in the Twenty First Century." American Journal of International Law 96, (2002): 798-816.

Caron, David D. “Symposium - ILC's State Responsibility Articles: The ILC Articles on State Responsibility: The Paradoxical Relationship Between Form and Authority." American Journal of International Law 96, (2002): 857-873.

20 Dice Platón en República: "nunca es justo hacer daño a nadie”. 
Comisión de Derecho Internacional. Draft Articles on Responsibility of States for International Wrongful Acts. Recuperado de http://legal.un.org/ ilc/texts/instruments/english/commentaries/9_6_2001.pdf

Comisión de Derecho Internacional. Draft Articles on the Responsibility of International Organizations. Recuperado de http://legal.un.org/ilc/ texts/instruments/english/draft_articles/9_11_2011.pdf

Comisión de Derecho Internacional. First Report on Succession of States in Respect of State Responsibility. Recuperado de http://legal.un.org/ docs $/$ ?symbol=A/CN.4/708

Corte Internacional de Justicia. Barcelona Traction, Light and Power Company, Limited (Belgium v. Spain) (New Application: 1962). Recuperado de http://www.icj-cij.org/en/case/50

Corte Internacional de Justicia. Case Concerning Application of the Convention on the Prevention and Punishment of the Crime of Genocide (Bosnia and Herzegovina V. Serbia and Montenegro). Recuperado de http://www. icj-cij.org/files/case-related/91/091-20070226-JUD-01-00-EN.pdf

Corte Internacional de Justicia. Corfu Channel (United Kingdom of Great Britain and Northern Ireland v. Albania). Recuperado de http://www. icj-cij.org/en/case/1

Corte Internacional de Justicia. Military and Paramilitary Activities in and against Nicaragua (Nicaragua v. United States of America), Recuperado de http://www.icj-cij.org/en/case/70/judgments

Damrosch, Lori \& Murphy, Sean D. International Law Cases and Materials. St. Paul: West Academic, 2014.

Freedom House. Freedom in the World 2018. Venezuela. Recuperado de https:// freedomhouse.org/report/freedom-world/2018/venezuela

Gassama, Ibrahim J. "Dealing with the World as It Is: Reimagining Collective International Responsibility." Washington University Global Studies Law Review 12, (2013): 695-753.

Grant, Thomas D. "International Responsibility and the Admission of States to the United Nations." Michigan Journal of International Law 30, (2009): 1095-1185.

Habermas, Jürgen. "El concepto de dignidad humana y la utopía realista de los derechos humanos", Diánoia 55, no. 64 (2010): 3-25.

Hakimi, Monica. "Toward a Legal Theory on the Responsibility to Protect." Yale Journal of International Law 39, no. 2 (2014): 247-280.

International Centre for Settlement of Investment Disputes, Biwater Gauff (Tanzania) Ltd. v. United Republic of Tanzania, ICSID Case no. $A R B / 05 / 22$. Recuperado de https://www.italaw.com/cases/157 
Jorgensen, Nina H.B. "Obligations of States and Organizations under the Law of International Responsibility." En Responsibility to Protect from Principle to Practice, compilado por Julia Hoffman y André Nollkaemper, 125-137. Amsterdam: Pallas Publications.

McCormick, Alison. "From Sovereignty to Responsibility: An Emerging International Norm and Its Call to Action in Burma." Indiana Journal of Global Legal Studies 18, no. 1 (2011): 563-591.

Murphy, Sean D. "Recent books on international law. Book review: 'The Law of International Responsibility'." American Journal of International Law 106, no. 4 (2012): 885-890.

Nelson, Jason C. "The United Nations and the Employment of Sanctions as a Tool of International Statecraft: Social Power Theory as a Predictor of Threat Theory Utility." Law and Psychology Review 29 (2005): 105-153. Recuperado de http://www.scielo.org.mx/scielo. php? script $=$ sci_arttext\&pid $=$ S0185-24502010000100001

Nieto-Navia, Rafael. Estudios sobre derecho internacional público. Bogotá: Editorial Pontificia Universidad Javeriana, 1993.

Organización de Estados Americanos. Carta de la Organización de Estados Americanos. Recuperado de http://www.oas.org/dil/esp/afrodescendientes_manual_formacion_lideres_anexos.pdf

Organización de Naciones Unidas. 2005 World Summit Outcome. Recuperado de http://www.un.org/en/development/desa/population/ migration/generalassembly/docs/globalcompact/A_RES_60_1.pdf

Organización de Naciones Unidas. A 63/677 del 12 de enero de 2009. Recuperado de https://undocs.org/A/63/677

Organización de Naciones Unidas. Declaración universal de derechos humanos. Recuperado de http://www.un.org/es/universal-declarationhuman-rights /

Organización de Naciones Unidas. Resolución 1267 de 1999. Recuperado de https://www.un.org/sc/suborg/en/s/res/1267-\%281999\%29

Organización de Naciones Unidas. Resolución 2625 de 1970. Recuperado de http://www.un-documents.net/a25r2625.htm

Organización de Naciones Unidas. Resolución 43/131 de 1988. Recuperado de http://www.un.org/documents/ga/res/43/a43r131.htm

Organización de Naciones Unidas. Resolución 45/ 100 de 1990. Recuperado de http://www.un.org/documents/ga/res/45/a45r100.htm

Platón, República. Ciudad de México: Porrúa, 2012. 
Stanley, Christopher J. "Book Review: The Relationship Between State and Individual Responsibility for International Crimes." Columbia Journal of International Law 48, (2010): 655-660.

Szigeti, Peter D. "Territorial Bias in International Law: Attribution in State and Corporate Responsibility." Journal of Transnational Law and Policy 19, (2010): 311-355.

Verdier, Pierre-Hugues. "Cooperative States: International Relations, State Responsibility and the Problem of Custom." Virginia Journal of International Law Association 42, (2002): 839-867.

Sucharitkul, Sompong. "State Responsibility and International Liability under International Law." Loyola of Los Angeles International \& Comparative Law Review, 18 (1996): 821-839.

Téllez-Núñez, Andrés. El problema de la efectividad del derecho internacional público. Bogotá: Editorial Pontificia Universidad Javeriana, 2008.

Téllez-Núñez, Andrés. Introducción al derecho internacional económico. Bogotá: Editorial Pontificia Universidad Javeriana e Ibañez, 2013 